\title{
Solubility Enhancement of BCS Classified II/IV Drug - Solid Dispersion of Apixaban by Solvent Evaporation
}

\author{
Amit Vinayak Asati ${ }^{1, *}$, Kishor Sahebrao Salunkhe ${ }^{2}$, Machindra Jairam Chavan ${ }^{1}$, Ravindra Bhausaheb Chintamani ${ }^{1,3}$, Rudra Pratap Singh ${ }^{4}$ \\ 'Amrutvahini College of Pharmacy, Sangamner, Maharashtra, INDIA. \\ ${ }^{2}$ Sanjivani College of Pharmaceutical Education and Research, Kopargaon, Maharashtra, INDIA. \\ ${ }^{3}$ Rajmata Jijau Shikshan Prasarak Mandal's, Institute of Pharmacy, Pune, Maharashtra, INDIA. \\ ${ }^{4}$ Columbia Institute of Pharmacy, Raipur, Chhattisgarh, INDIA.
}

\begin{abstract}
Background: Solubility is an important physico-chemical factor affecting absorption of drug and its therapeutic effectiveness. One of the major problems responsible for the low turnout in the development of new molecular entities as drug formulations is poor solubility and poor permeability of the lead compounds. Objectives: The present research work was aimed to enhance the solubility of Apixaban drug by using Solid Dispersion Technique. Methods: The solid dispersion is the technique for the formulation of water insoluble drugs to enhance their aqueous solubility, absorption as well as dissolution rate, which leading to enhancement of bioavailability of drugs as compared to conventional directly compressed tablets. In this study, Apixaban was opted for formulating Solid dispersion with Hydrophilic polymers like HPMC E50 LV, HPMC E5, PEG 6000 and PVP K-30 by Spray drying method using a structured I optimal screening DOE. To screen out the ratio of polymer and suitable polymer type for solid dispersion resulted into highest solubility as a response. Results: The Solid dispersion of Apixaban showed improvement in the solubility in water
\end{abstract}

by multiple folds when Apixaban used in combination with Hydrophilic polymers. The Apixaban solid dispersion with polymer HPMC K15M resulted into highest increase in the solubility as compared to the other evaluated hydrophilic polymers. Conclusion: From the present study, we can concluded that the optimized Apixaban solid dispersion may prove to be a suitable potential option for solubility enhancement, increased in-vitro drug release and effective delivery of BCS class II and IV drugs.

Key words: Apixaban, Solubility enhancement, Solid Dispersion.

Correspondence

Mr. Amit Vinayak Asati

PhD Research Scholar, Amrutvahini College of Pharmacy, Sangamner Ahmednagar - 422608, Maharashtra, INDIA.

Phone no: +91- 9870258695

Email: avasati28@rediffmail.com

DOI: 10.5330/ijpi.2020.4.76

\section{INTRODUCTION}

Therapeutic effectiveness of a drug depends on its bioavailability as well as on the solubility of drug molecules. Solubility is the phenomenon of dissolution of solute in the solvent to give a homogenous system and is one of the important parameter to achieve the desired concentration of drug in the systemic circulation to produce a pharmacological response. Nearly $40 \%$ of the new chemical entities currently being discovered have poor solubility in water. More than one-third of the drugs listed in the U.S. Pharmacopoeia fall into the poorly water-soluble or water-insoluble categories. Low aqueous solubility is the major problem encountered with formulation development of new chemical entities as well as for the generic development. To achieve high absorption of a drug, it should be present in the form of an aqueous solution at the site of absorption. ${ }^{1}$ The insufficient dissolution rate of the drug is the limiting factor in the oral bioavailability of poorly water soluble compounds. In such cases, dose escalation would be required until the blood drug concentration reaches the therapeutic drug concentration range. This dose escalation sometimes causes topical toxicity in the gastrointestinal tract upon oral administration and such toxicity could lead to a reduction in patient compliance. The formulation design of a drug product with high dose is generally difficult due to significant higher tablet weight. Increasing drug load might result in poor powder properties and may have different in-process challenges during granulation and compression. In addition to this, the manufacturing cost would also increase since a large amount of active pharmaceutical ingredient (API) might be consumed to develop and manufacture the drug product. The poor solubility of new drug candidates might also affect the chemical properties during the drug discovery stage. During clinical trials; the poor solubility and bioavailability of a drug substance might result in limited therapeutic potential, thereby leading to insufficient clinical outcomes. ${ }^{2}$

Different factors affecting solubility, solubility enhancement techniques, its importance and applications has been reported for poorly water soluble drugs. ${ }^{3-7}$

Amorphous solid dispersions can be classified according to the molecular interaction of drug and carriers in solid solutions, solid suspensions or a mixture of both. The use of polymers in the preparation of a true solid solution creates an amorphous product in which the crystalline drug is dissolved. This type of amorphous solid dispersion is homogeneous on a molecular level. The solid dispersions systems are able to reduce the drug particle size to nearly a molecular level, to solubilize or co-dissolve the drug by the water soluble carrier, to provide better wettability and disposability of the drug by the carrier material and to produce amorphous forms of the drug and carriers. In these solid dispersions, the carrier dissolution (or mixtures of carriers) dictates the drug release profile. ${ }^{8}$

Polymeric carriers have been the most successful for solid dispersions, because they are able to originate amorphous solid dispersions. They are divided into fully synthetic polymers and natural productbased polymers. Fully synthetic polymers include povidone (PVP), polyethylene glycols (PEG) and poly-methacrylates. Natural product based polymers are mainly composed by cellulose derivatives, 
such as hydroxypropyl methylcellulose (HPMC), ethyl cellulose or hydroxypropyl cellulose or starch derivates like cyclodextrins.

Use of solid dispersion with hydrophilic polymer like HPMC E50 LV, HPMC E5, PEG 6000 and PVP K-30 has been investigated as a potential means to increase the solubility of poorly soluble drugs and to stabilize the amorphous drug delivery system.

Various methods are available for incorporation of drugs into solid dispersion like melting and solvent evaporation methods. Solid dispersions are one of the most promising strategies to improve the oral bioavailability of poorly water soluble drugs. By reducing drug particle size to the absolute minimum and hence improving drug wettability, bioavailability may be significantly improved. ${ }^{8}$

\section{MATERIALS AND METHODS}

\section{Materials}

Apixaban was obtained as a gift samples from Dr. Reddys Laboratories Limited, Hyderabad, India. The polymer like HPMC E50 LV, HPMC E5, PEG 6000, PVP K-30 and solvents like Ethanol, Acetonitrile, Methanol, Dichloromethane, DMSO, Acetone were of analytical grade and procured from SD Fine Chem Limited, Mumbai, India.

\section{Method}

\section{Solvent selection for Solid dispersion}

The solvent selection is most important considering the solubility of drug and polymer. Different organic solvents Acetonitrile (ACN), Dichloromethane (DCM) and Methanol were evaluated for preparation of solid dispersion. ${ }^{10}$

\section{Polymer selection for Solid dispersion}

Different water soluble polymers like HPMC E-50 LV, PVP K30, HPMC E-5 and PEG- 6000 were evaluated for preparation of solid dispersion. Different organic solvents Acetonitrile (ACN), Dichloromethane (DCM) and Methanol were initially used as a solvent to dissolve polymer and Apixaban for polymer screening. The initial screening trials for selection of polymer and solvents are presented in Table 1.,10

\section{Procedure for preparation of Solid dispersion}

- Separately weigh $100 \mathrm{mg}$ of polymer and $100 \mathrm{mg}$ of Apixaban.
- First dissolved the Polymer in $40 \mathrm{ml}$ of dichloromethane under stirring.

- Then the Apixaban was dissolved in the polymer solution under stirring for $30 \mathrm{~min}$.

- The drug polymer solution is dried in Spray dryer with the parameters as mentioned in the Table 2.

- The obtained drug polymer solid dispersion is further dried in vacuum oven at $60^{\circ} \mathrm{C}$ to evaporate the residual solvent.

- Post complete removal of solvent, the solid dispersion was collected and sifted through \#20 sieve.

- The polymer was selected based on the solubility of the solid dispersion.

\section{Drug Polymer ratio selection by Screening DOE}

The selected all polymers are showing considerable increase in the solubility as compared to the plain drug. However, based on initial learning; the ratio of API to Polymer and polymer type were selected as a factor for the DOE and solubility of each DoE run is considered as a response to the DOE. The API concentration i.e. $10 \mathrm{mg}$ is considered to be constant for all run and the other 4 polymers were varied with different concentration. Considering the learning from earlier experiments with different solvent; DCM is finalized as a solvent and was kept constant to all DOE run. The selected I-Optimal screening DOE designed to screen out the Optimum concentration of polymer and polymer type are presented in Table 3-5. The statistical optimization of various process parameters for the experiment was done using Design-Expert software. Based on the DoE outcome; the selected Drug Polymers ratio for API (10mg): PVP K30 (40mg) and API (10mg): HPMC E50 LV (40mg) with Dichloromethane (DCM) solvent were scale up by spray drying technique.

\section{Evaluation of apixaban solid dispersion Solubility Study}

The plain Apixaban and prepared trials of Apixaban Solid dispersion were evaluated for comparative solubility study in distilled water. The excess amount of solid dispersion was added to $5 \mathrm{ml}$ water and agitated in a thermostatically controlled shaker with a temperature maintained at $35^{\circ} \mathrm{C}$. After $48-\mathrm{hr}$ equilibrium, the saturated solution was rapidly filtered

Table 1: Trials for selection of Polymer and Solvent for Apixaban Solid dispersion.

\begin{tabular}{cccccc}
\hline Trial & Different Polymers & $\begin{array}{c}\text { Ratio } \\
\text { (Drug: Polymer) }\end{array}$ & $\begin{array}{c}\text { Drug Quantity } \\
(\mathbf{m g})\end{array}$ & $\begin{array}{c}\text { Polymer Quantity } \\
(\mathbf{m g})\end{array}$ & $\begin{array}{c}\text { Different } \\
\text { Solvents } \\
(60 \mathrm{ml})\end{array}$ \\
\hline 1 & PVP K30 & $1: 1$ & 100 & 100 & ACN \\
2 & PVP K30 & $1: 1$ & 100 & 100 & DCM \\
3 & PVP K30 & $1: 1$ & 100 & 100 & Methanol \\
4 & HPMC E-50 LV & $1: 1$ & 100 & 100 & ACN \\
5 & HPMC E-50 LV & $1: 1$ & 100 & 100 & DCM \\
6 & HPMC E-50 LV & $1: 1$ & 100 & 100 & Methanol \\
7 & HPMC E-5 & $1: 1$ & 100 & 100 & ACN \\
8 & HPMC E-5 & $1: 1$ & 100 & 100 & DCM \\
9 & HPMC E-5 & $1: 1$ & 100 & 100 & Methanol \\
10 & PEG- 6000 & $1: 1$ & 100 & 100 & ACN \\
11 & PEG- 6000 & $1: 1$ & 100 & 100 & DCM \\
12 & PEG- 6000 & $1: 1$ & 100 & 100 & Methanol \\
\hline
\end{tabular}


through a $0.45-\mu \mathrm{m}$ millipore filter and diluted with distilled water and it was analysed by UV Spectrophotometer at $278 \mathrm{~nm} .{ }^{11-14}$

\section{Drug content}

Based on the obtaining data from the solubility study of Apixaban Solid dispersion, the optimize batch was further evaluated for drug content. The test was estimated by dispersing $50 \mathrm{mg}$ of formulation in $20 \mathrm{ml}$ of methanol, sonicated for $10 \mathrm{~min}$. Then it is filtered using $0.45 \mu \mathrm{m}$ filter and further diluted with phosphate buffer. Then, the sample was diluted and analysed by UV spectrophotometer at $278 \mathrm{~nm}$. The Drug content and entrapment efficiency was calculated by following formula:

Total Drug Loading $(\%)=\frac{\text { Weight of Drug }}{\text { Weight of Drug }+ \text { Weight of polymer }} \times 100$

Drug content $(\%)=\frac{\text { Weight of drug in dispersion }}{\text { weight of solid dispersion }} \times 100$

Entrapment efficiency $(\%)=\frac{\text { Weight of drug in dispersion }}{\text { initial weight of drug }} \times 100$

\section{In vitro drug release Study}

The in-vitro drug release was performed in USP apparatus Type II (Electrolab Dissolution tester USP TDT-08L) using paddle method at 75 rpm of rotation speed. The phosphate buffer $\mathrm{pH} 6.8(900 \mathrm{~mL})$ was used as a dissolution medium and media temperature maintained at $37 \pm 0.5^{\circ} \mathrm{C}$ during the study. Accurately weighed amount of the Apixaban plain drug and solid dispersion (all equivalent to $10 \mathrm{mg}$ of Apixaban) were transferred into separate vessels of dissolution apparatus. $10 \mathrm{~mL}$ aliquot was removed at predetermined time intervals i.e 10, 20, 30, 40, 50, 60 and $90 \mathrm{~min}$ from dissolution medium and replace with same buffer solution maintained at $37 \pm 0.5^{\circ} \mathrm{C}$ for maintain sink condition and the samples were filtered through a $0.45-\mu \mathrm{m}$ millipore filter and analysed by using UV Spectrophotometer the wavelength of $278 \mathrm{~nm} \cdot{ }^{12-13,15}$

\section{Moisture Content}

Moisture content was determined at $0 \%$ relative humidity created with calcium carbonate in desiccator. The sample was kept in desiccator and observed the weight loss, $\%$ moisture content was calculated using following formula:

$\%$ moisture content $=\frac{\text { Initial weight }- \text { Final weight }}{\text { (Final weight })} \times 100$

FT-IR

FT-IR spectra are used for functional group identification in compound. A small amount of in the form of powder was placed on selenium

Table 2: Spray Drying Parameter for Trial Batches.

\begin{tabular}{cc}
\hline Spray Drying Parameter & Observed Value \\
\hline Solid conc. in Dichloromethane & $5 \%$ \\
Inlet temp. & $47^{\circ} \mathrm{C}$ \\
Outlet temp. & $40^{\circ} \mathrm{C}$ \\
Inlet High & $100^{\circ} \mathrm{C}$ \\
Outlet High & $70^{\circ} \mathrm{C}$ \\
Aspirator Flow rate & $45 \mathrm{~nm}^{3}$ \\
Feed Pump Flow Rate & $1 \mathrm{ml} / \mathrm{min}$ \\
D Block ON & $1 \mathrm{sec}$ \\
D Block OFF & $90 \mathrm{sec}$ \\
\hline
\end{tabular}

bromide crystal. A vertical rod was pulled down in drug sample placed over crystal. FT-IR spectrum was run. The obtained IR spectrum was smoothened. Finally, functional groups were detected by comparing the obtained IR ranges with reference ranges available. ${ }^{12}$

\section{Differential scanning calorimetry (DSC)}

The DSC was performed by using Mettler Toledo (DSC 8-32-3). DSC measurements were performed by weighing $2 \mathrm{mg}$ of each sample in an aluminium seal heated over a temperature gradient (from $10-300^{\circ} \mathrm{C}$ at a heating rate of $10^{\circ} \mathrm{C} / \mathrm{min}$.) using DSC apparatus and under an inert atmosphere (nitrogen) at a flow rate of $100 \mathrm{ml} / \mathrm{min}^{.9,12}$

\section{RESULTS}

\section{Solvent selection for Solid dispersion}

The initial screening of different organic solvents Acetonitrile (ACN), Dichloromethane (DCM) and Methanol are based on giving a clear solution after dissolving the drug and polymer. The initial screening trials results for selection of Organic solvents are presented in below Table 6.

\section{Polymer selection for Solid dispersion}

The initial screening of different water soluble polymers like HPMC E-50 LV, PVP K30, HPMC E-5 and PEG- 6000 are giving clear solution for the dissolved drug and polymer. The initial screening trials results for selection of polymer and solvent are presented in Table 6 .

From the above initial screening, it is evident that the maximum solubility is observed in the solid dispersion with HPMC E-50LV and PVP K30 polymer in DCM solvent. Hence, further these polymers and DCM solvents were selected for further studies.

\section{DOE Screening Apixaban Solid dispersion by Solubility}

The comparative solubility results for the selected I-Optimal screening DOE are presented in Table 7.

\section{DOE statistical interpretation:}

ANOVA table and Graphical analysis are presented in the Figure 1, Figure 2, respectively. It was observed that High level of the polymer to API ratio tends to decrease the response. Ratio of polymer to API is negatively impacted on response.

The API to polymer ratio 0.25 of both Apixaban (10mg): PVP K30 (40mg) (batch no. APX75) and Apixaban (10mg): HPMC E-50 LV (40mg) (batch no. APX71) was selected for preparation of the solid dispersion as it has highest water solubility $336.20 \mu \mathrm{g} / \mathrm{ml}$ and $352.03 \mu \mathrm{g} /$ $\mathrm{ml}$, respectively and the same ratio was selected for further evaluation studies.

Table 3: I-optimal DOE screening design.

\begin{tabular}{ccccc}
\hline File Version & 12.0 .3 .0 & & & \\
Study Type & $\begin{array}{c}\text { Response } \\
\text { Surface }\end{array}$ & Subtype & Randomized \\
Design Type & I-optimal & $\begin{array}{c}\text { Point } \\
\text { Exchange }\end{array}$ & Runs & 17 \\
$\begin{array}{c}\text { Design } \\
\text { Model }\end{array}$ & 2FI & Blocks & No Blocks \\
$\begin{array}{c}\text { Build Time } \\
(\text { ms })\end{array}$ & 36.00 & & & \\
\hline
\end{tabular}




\section{Evaluation of Apixaban Solid Dispersion Solubility}

Excess amount of solid dispersion was added to $5 \mathrm{ml}$ water, sonicated for $1 \mathrm{hr}$. and agitated in a thermostatically controlled shaker with a temperature maintained at $35^{\circ} \mathrm{C}$ for $72 \mathrm{hr}$. The suspension was filtered through $0.45 \mu \mathrm{m}$ filter and diluted with water and analysed to determine concentration by UV-spectrophotometer at $278 \mathrm{~nm}$. The comparative solubility of pure Apixaban drug and final selected Solid dispersion are mentioned in the Table 8.

The Apixaban (10mg) + HPMC E50 LV (40mg) (batch no. APX71) solid dispersion shows the more solubility than that of Apixaban (10mg) + PVP K30 (40mg) (batch no. APX75) by spray drying method is use for further study.

\section{Drug Content}

The calculated Drug content and entrapment efficiency for batch no. APX71 are presented in Table 9. The observed entrapment efficiency of solid dispersion for batch no. APX71 was found to be $99.22 \%$.

\section{Dissolution Profile}

The comparative dissolution profile of plain drug (batch no. APX) and the solid dispersion (batch no.APX71) are presented in Figure 3.

\section{Moisture Content}

Moisture content of batch no. APX71 A Apixaban (10mg) + HPMC E50

LV (40mg)\} spray dried solid dispersion was found to be $3.67 \%$.

FT-IR

In the Figure 4, observed the FT-IR spectral peaks of Apixaban were taken on IR spectrophotometer by simply placing small amount of drug in powder form on selenium bromide crystal. In a spectra peaks were found at 1679.19 for $\mathrm{C}=\mathrm{O}$ stretching, 3472.30 for $\mathrm{N}-\mathrm{H}$ stretching.

Table 4: Selected Factors and its range for I-optimal DOE screening design.

\begin{tabular}{ccccc}
\hline Factor & Name & Type & Minimum & Maximum \\
\hline \multirow{2}{*}{ A } & $\begin{array}{c}\text { Ratio of API to } \\
\text { Polymer }\end{array}$ & Numeric & 0.2500 & 1.000 \\
& & & \\
& & & PVP K30, & \\
& & & HPMC & \\
B & Polymer Type & Categoric & E50 LV, & \\
& & & PEG-6000, \\
& & & HPMC E-5 \\
\end{tabular}

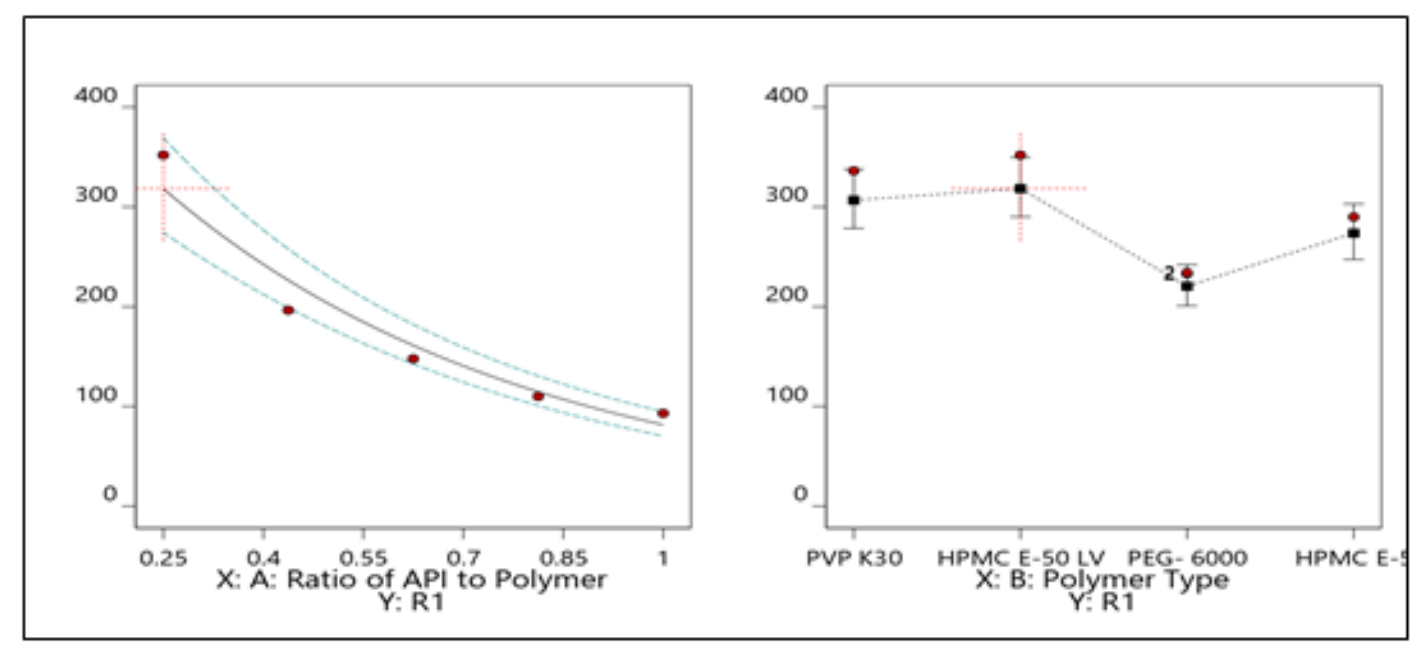

Figure 1: Model Graph (Ratio of Polymer to API at LOW level 0.25).

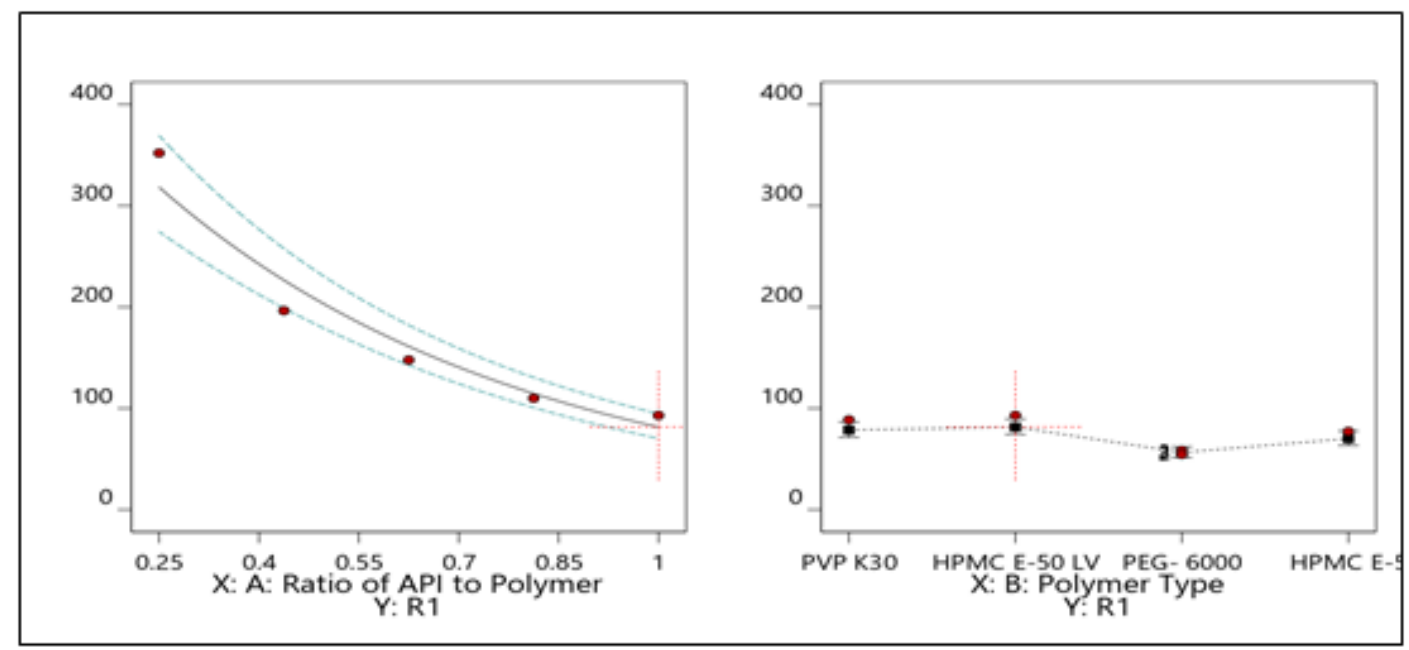

Figure 2: Model Graph (Ratio of Polymer to API HIGH level-1.0). 


\section{Differential Scanning Calorimetry (DSC)}

DSC measurements were performed by weighing $2 \mathrm{mg}$ of each sample in an aluminium seal heated over a temperature gradient (from $10-300^{\circ} \mathrm{C}$ at a heating rate of $10^{\circ} \mathrm{C} / \mathrm{min}$ ) using DSC apparatus (METTLER) and under an inert atmosphere (nitrogen) at a flow rate of $100 \mathrm{ml} / \mathrm{min}$. The complete disappearance of the melting peak (Figure 5) was observed in DSC thermograph of solid dispersion, which indicates the complete inclusion of the drug molecules within the system. The observations demonstrating that the formulation was in the amorphous state.

\section{DISCUSSION}

There is improvement in the solubility of Apixaban was observed for initial formulation trial of solid dispersion of Apixaben by solvent evaporation with Spray drying. The initial screening of different organic solvents Acetonitrile (ACN), Dichloromethane (DCM) and Methanol were performed with different polymers PVP K30, HPMC E-50 LV, HPMC E-5 and PEG- 6000 results into solubility enhancement. ${ }^{9,10}$ However, the maximum solubility was observed for trial batches with HPMC E-50LV and PVP K30 polymer with DCM solvent.Further the

\begin{tabular}{|c|c|c|c|c|c|}
\hline \multirow{2}{*}{$\begin{array}{l}\text { DOE } \\
\text { Run }\end{array}$} & Factor A & Factor B & \multirow{2}{*}{$\begin{array}{c}\text { Corresponding } \\
\text { Drug Quantity (mg) }\end{array}$} & \multirow{2}{*}{$\begin{array}{l}\text { Corresponding } \\
\text { Polymer Quantity } \\
\text { (mg) }\end{array}$} & \multirow{2}{*}{$\begin{array}{c}\text { Response } \\
\text { Solubility } \\
(\mu \mathrm{g} / \mathrm{ml})\end{array}$} \\
\hline & $\begin{array}{c}\text { A:Ratio of API to } \\
\text { polymer }\end{array}$ & B:Polymer type & & & \\
\hline 1 & 1 & PEG- 6000 & 10 & 10 & \multirow{17}{*}{$\begin{array}{l}\text { Solubility } \\
(\mu \mathrm{g} / \mathrm{ml}) \text { to be } \\
\text { evaluated. }\end{array}$} \\
\hline 2 & 0.625 & PVP K30 & 10 & 16 & \\
\hline 3 & 0.8125 & HPMC E-50 LV & 10 & 12.3 & \\
\hline 4 & 0.625 & PEG- 6000 & 10 & 16 & \\
\hline 5 & 1 & HPMC E-5 & 10 & 10 & \\
\hline 6 & 0.25 & HPMC E-50 LV & 10 & 40 & \\
\hline 7 & 1 & HPMC E-50 LV & 10 & 10 & \\
\hline 8 & 0.625 & HPMC E-50 LV & 10 & 16 & \\
\hline 9 & 0.25 & PEG- 6000 & 10 & 40 & \\
\hline 10 & 1 & PEG- 6000 & 10 & 10 & \\
\hline 11 & 1 & PVP K30 & 10 & 10 & \\
\hline 12 & 0.25 & PVP K30 & 10 & 40 & \\
\hline 13 & 0.625 & HPMC E-5 & 10 & 16 & \\
\hline 14 & 0.8125 & PVP K30 & 10 & 12.3 & \\
\hline 15 & 0.25 & HPMC E-5 & 10 & 40 & \\
\hline 16 & 0.4375 & HPMC E-50 LV & 10 & 22.85 & \\
\hline 17 & 0.25 & PEG- 6000 & 10 & 40 & \\
\hline
\end{tabular}

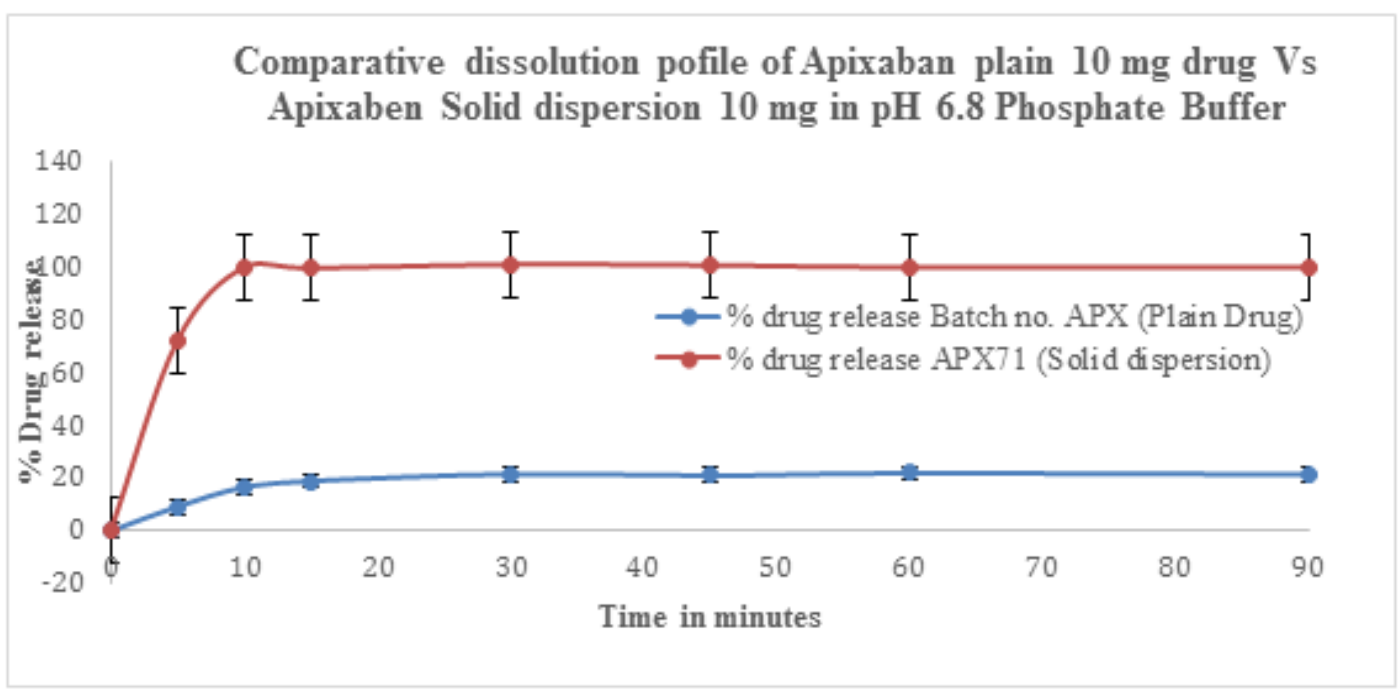

Figure 3: Comparative dissolution profile of plain drug (batch no. APX) and solid dispersion (batch no. APX71)

The batch no. APX71 \{Solid dispersion of Apixaban (10mg) + HPMC E50 LV (40mg)\} shows slightly higher and complete drug release $101.00 \pm 0.15 \%(n=3)$ in $45 \mathrm{~min}$. as compared to the plain drug $21.12 \pm 0.75 \%(n=3)$. 
Table 6: Trials for selection of Solvent and Polymer for Apixaban Solid dispersion.

\begin{tabular}{ccccccc}
\hline $\begin{array}{c}\text { Batch } \\
\text { no. }\end{array}$ & $\begin{array}{c}\text { Different } \\
\text { Polymers }\end{array}$ & $\begin{array}{c}\text { Ratio } \\
\text { (Drug: } \\
\text { Polymer) }\end{array}$ & $\begin{array}{c}\text { Drug } \\
\text { Quantity } \\
(\mathbf{m g})\end{array}$ & $\begin{array}{c}\text { Polymer } \\
\text { Quantity } \\
(\mathbf{m g})\end{array}$ & $\begin{array}{c}\text { Different } \\
\text { Solvents } \\
(60 \mathrm{ml})\end{array}$ & $\begin{array}{c}\text { Solubility } \\
(\mu \mathrm{g} / \mathrm{ml}), \\
\text { Mean } \pm \text { SD (N=3) }\end{array}$ \\
\hline APX50 & PVP K30 & $1: 1$ & 100 & 100 & CAN & $74.25 \pm 0.76$ \\
APX51 & PVP K30 & $1: 1$ & 100 & 100 & DCM & $88.72 \pm 0.64$ \\
APX52 & PVP K30 & $1: 1$ & 100 & 100 & Methanol & $77.16 \pm 0.48$ \\
APX53 & HPMC E-50 LV & $1: 1$ & 100 & 100 & CAN & $75.44 \pm 0.98$ \\
APX54 & HPMC E-50 LV & $1: 1$ & 100 & 100 & DCM & $93.02 \pm 0.84$ \\
APX55 & HPMC E-50 LV & $1: 1$ & 100 & 100 & Methanol & $81.90 \pm 0.48$ \\
APX56 & HPMC E-5 & $1: 1$ & 100 & 100 & CAN & $62.20 \pm 0.39$ \\
APX57 & HPMC E-5 & $1: 1$ & 100 & 100 & DCM & $77.21 \pm 0.86$ \\
APX58 & HPMC E-5 & $1: 1$ & 100 & 100 & Methanol & $66.91 \pm 0.59$ \\
APX59 & PEG- 6000 & $1: 1$ & 100 & 100 & CAN & $49.90 \pm 0.37$ \\
APX60 & PEG- 6000 & $1: 1$ & 100 & 100 & DCM & $58.36 \pm 0.97$ \\
APX67 & PEG- 6000 & $1: 1$ & 100 & 100 & Methanol & $53.19 \pm 0.88$ \\
\hline
\end{tabular}

Table 7: Screening DoE for polymer concentration and polymer type used for preparation of Apixaban solid dispersion.

\begin{tabular}{|c|c|c|c|c|}
\hline $\begin{array}{l}\text { DOE } \\
\text { Run }\end{array}$ & Batch no. & $\begin{array}{l}\text { Factor } 1 \\
\text { A:Ratio } \\
\text { of API to } \\
\text { polymer }\end{array}$ & $\begin{array}{c}\text { Factor } 2 \\
\text { B:Polymer type }\end{array}$ & $\begin{array}{c}\text { Response } 1 \\
\text { Solubility }(\mu \mathrm{g} / \\
\mathrm{ml}), \\
\text { Mean } \pm \mathrm{SD}(\mathrm{N}=3)\end{array}$ \\
\hline 1 & APX60 & 1 & PEG- 6000 & $58.36 \pm 0.69$ \\
\hline 2 & APX68 & 0.625 & PVP K30 & $130.67 \pm 0.38$ \\
\hline 3 & APX69 & 0.8125 & HPMC E-50 LV & $109.98 \pm 0.55$ \\
\hline 4 & APX70 & 0.625 & PEG- 6000 & $95.83 \pm 0.91$ \\
\hline 5 & APX57 & 1 & HPMC E-5 & $77.21 \pm 0.86$ \\
\hline 6 & APX71 & 0.25 & HPMC E-50 LV & $352.03 \pm 0.48$ \\
\hline 7 & APX54 & 1 & HPMC E-50 LV & $93.02 \pm 0.84$ \\
\hline 8 & APX72 & 0.625 & HPMC E-50 LV & $147.77 \pm 0.77$ \\
\hline 9 & APX73 & 0.25 & PEG- 6000 & $232.96 \pm 0.40$ \\
\hline 10 & APX74 & 1 & PEG- 6000 & $54.55 \pm 0.84$ \\
\hline 11 & APX51 & 1 & PVP K30 & $88.72 \pm 0.64$ \\
\hline 12 & APX75 & 0.25 & PVP K30 & $336.20 \pm 0.91$ \\
\hline 13 & APX76 & 0.625 & HPMC E-5 & $116.03 \pm 0.87$ \\
\hline 14 & APX77 & 0.8125 & PVP K30 & $102.77 \pm 0.54$ \\
\hline 15 & APX78 & 0.25 & HPMC E-5 & $289.90 \pm 0.93$ \\
\hline 16 & APX79 & 0.4375 & HPMC E-50 LV & $196.44 \pm 0.78$ \\
\hline 17 & APX80 & 0.25 & PEG- 6000 & $234.14 \pm 0.69$ \\
\hline
\end{tabular}

Table 8: Solubility of Sample.

\begin{tabular}{cc}
\hline Sample & $\begin{array}{c}\text { Solubility }(\mu \mathrm{g} / \mathrm{ml}), \\
\text { Mean } \pm \text { SD }(N=3)\end{array}$ \\
\hline Apixaban Plain drug & $2.86 \pm 0.13$ \\
Apixaban (10mg) + PVP K30 SD (40mg) & $336.20 \pm 0.91$ \\
Apixaban (10mg) + HPMC E50LV SD $(40 \mathrm{mg})$ & $352.03 \pm 0.48$ \\
\hline
\end{tabular}

Table 9: Drug Content for batch no. APX71.

\begin{tabular}{ccc}
\hline Sr. no. & Parameter & $\begin{array}{c}\text { Result }(\%), \text { Mean } \pm \text { SD } \\
(N=3)\end{array}$ \\
\hline 1 & Total drug loading & $14.28 \pm 0.22$ \\
2 & Drug Content & $14.17 \pm 0.31$ \\
3 & Entrapment Efficiency & $99.22 \pm 0.45$ \\
\hline
\end{tabular}

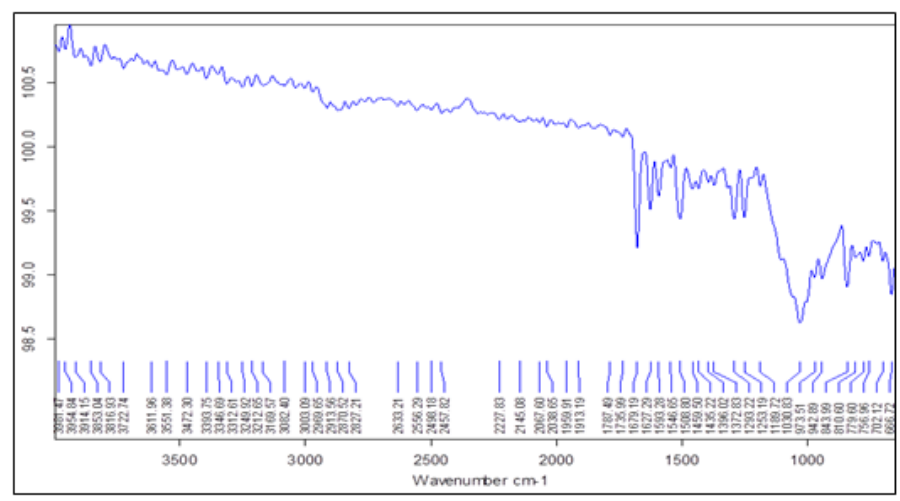

Figure 4: FT-IR Spectra of Apixaban Solid dispersion (batch no.APX71).

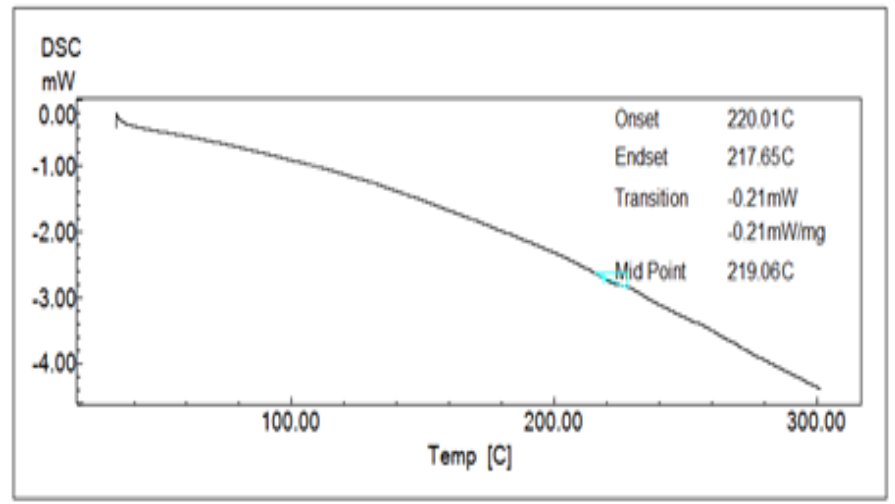

Figure 5: DSC of Apixaban Solid Dispersion (APX71). 
screening DOE was designed with the objective to screen out the best suitable ratio of solid dispersion giving highest solubility. The factors like ratio of API to Polymer (numerical) and polymer type (Categorical) were selected as a critical factor and solubility of each DoE run was considered as a response to the DOE. The API concentration i.e. $10 \mathrm{mg}$ and DCM were considered to be constant for all DOE run.

It was observed that High level of the polymer to API ratio tends to decrease the response. Ratio of polymer to API is negatively impacted on response. The API to polymer ratio 0.25 of Apixaban (10mg): HPMC E-50 LV (40mg) (batch no. APX71) was selected for preparation of the solid dispersion as it has highest water solubility $352.03 \mu \mathrm{g} / \mathrm{ml}$. The comparative dissolution profile of the solid dispersion (batch no. APX71) shows significantly higher and complete drug release in 45 min as compared to the plain drug (batch no. APX). ${ }^{12,13,15}$ The selected Solid dispersion were showing good drug entrapment efficiency and drug content. The IR spectra shows characteristics peaks of Apixaban at 1679.19 for $\mathrm{C}=\mathrm{O}$ stretching, 3472.30 for $\mathrm{N}-\mathrm{H}$ stretching. ${ }^{12}$ The DSC thermograph of solid dispersion shows complete disappearance of the melting peak which indicates the complete inclusion of the drug molecules within the system..$^{9,12}$ Hence, this demonstrated the formulation of amorphous state.

\section{CONCLUSION}

It may be concluded that the hydrophilic polymer HPMC E50 LV and Dichloromethane can be a best among the other evaluated polymer and organic solvent respectively for preparation and solubility enhancement by amorphous solid dispersion of Apixaban.

The success of the solubility enhancement and in vitro drug release studies recommends the method can be further used for formulation design by controlling the drug release from the final dosage form.

From the present study could conclude that the optimized Apixaban solid dispersion by solvent evaporation is a suitable potential option for solubility enhancement, increased in-vitro drug release and can be used for effective delivery of BCS class II/ IV drugs.

\section{ACKNOWLEDGEMENT}

The authors are acknowledging Amrutvahini College of Pharmacy, Sangamner, M.S. India for providing the financial facilities and also thank to the library of the college for providing e-sources available.

\section{CONFLICT OF INTEREST}

The authors declare no conflicts of interest.

\section{ABBREVIATIONS}

FTIR: Fourier Transform Infrared spectroscopy; PBS: Phosphate Buffered Saline; FE-SEM: Field Emission Scanning Electron Microscopy; HR-TEM: High Resolution Transmission Electron Microscopy; TGA: Thermo-Gravimetric Analysis; AFM: Atomic Forced Microscopy; XRDX-Ray Diffraction; PXRD: Powder X-ray Diffraction; PSA: Particle Size Analysis; MP: Melting Point; BP: Boiling Point; UV-Vis: Ultra Violet Visible; DSC: Differential Scanning Colorimetry; SD: Standard Deviation; ICH: International Conference on Harmonization; NDDS: Novel Drug Delivery System.

\section{REFERENCES}

1. Lachman $L$, Lieberman $H$, Kanig JL. The theory and practice of industrial pharmacy. 3rd Edition. 2003;458.

2. Yohei K, Koichi W, Manabu N, Shizuo Y, Satomi O. Formulation design for poorly water-soluble drugs based on biopharmaceutics classification system: Basic approaches and practical applications. Int J Pharm. 2011;420(1):1-10.

3. Savjani KT, Gajjar AK, Savjani JK. Review article on Drug Solubility: Importance and Enhancement Techniques. ISRN Pharm. 2012;195727:1-10.

4. Deepshikha S, Vaibhav S, Anand KA. Techinques for solubility enhancement of poorly soluble drugs. J Med Pharm Alli Scis. 2013;1:18-36.

5. Kadam SV, Shinkar DM. Review article on Solubility Enhancement technique. Int J Pharm Biol Sci. 2013;3(3):462-75

6. Bharti VP, Attal VR, Munde AV. Review article on strategies to enhance solubility and dissolution of poorly water soluble drug. J Innovations Pharm Biol Sci. 2015;1:2349-759

7. Shinkar DM, Patil AN, Saudagar RB. Solubility Enhancement by Solid Dispersion. Asian J Pharm Technol. 2017;7(2):72-6.

8. Vasconcelos T, Sarmento B, Costa P. Reviews- Solid dispersions as strategy to improve oral bioavailability of poor water soluble drugs. Drug Discovery Today. 2007;12(23/24):1-6.

9. Leuner C, Dressman J. Improving drug solubility for oral delivery using solid dispersions. Eur J Pharm Biopharm. 2000;50(1):47-60.

10. Singh A, Mooter GVD. Spray drying formulation of amorphous solid dispersions. Adv Drug Deliv Rev.2016;100:27-50.

11. Liu H, Edgar KJ, Taylor LS. The role of polymers in oral bioavailability enhancement: A review. Polymer. 2015;77:399-415.

12. Yin L, Huang SJ, Zhu CL, Zhang SH, Zhan GQ, Chen XJ, et al. In vitro and in vivo studies on a novel solid dispersion of repaglinide using polyvinylpyrrolidone as the carrier. Drug Dev Ind Pharm. 2012;38(11):1371-80

13. Lachman L, Lieberman $H$, Schwartz JB. Pharmaceutical dosages form tablet. 1999;1:47-9.

14. Protocol to conduct equilibrium solubility experiments for the purpose of biopharmaceutics classification system-based classification of active pharmaceutical ingredients for bio waiver. Working document QAS/17.699/Rev. 2018.

15. USFDA Dissolution Recommended conditions for Apixaban tablet. https:// www.accessdata.fda.gov/scripts/cder/dissolution/dsp_SearchResults.cfm.

Article History: Submission Date : 19-03-2020; Revised Date : 08-07-2020; Acceptance Date : 28-09-2020.

Cite this article: Asati AV, Salunkhe KS, Chavan MJ, Chintamani RB, Singh RP. Solubility Enhancement of BCS Classified II/IV Drug-Solid Dispersion of Apixaban by Solvent Evaporation. Int. J. Pharm. Investigation, 2020;10(4):430-6. 